\title{
A Study for Optimizing a Stand-Alone Hybrid Photovoltaic-Diesel System to Feed Summer Loads
}

\author{
G. Delvecchio ${ }^{2}$, M. Guerra ${ }^{3}$, C. Lofrumento ${ }^{1}$, F. Neri ${ }^{1}$ \\ ${ }^{1}$ Department of Electrotechnics and Electronics - Polytechnic of Bari \\ Via E. Orabona n. 4 - 70125 Bari (Italy) \\ phone: +39080 5963256, fax: +390805963410, e-mail: neri@deemail.poliba.it \\ ${ }^{2}$ Technical Area - University of Bari \\ Piazza Umberto I n.1 - 70100 Bari (Italy) \\ phone:+39 080 5714648, fax:+39 080 5714655, e-mail: g.delvecchio@area-tecnica.uniba.it \\ ${ }^{3}$ ENEA - Experimental Area Monte Aquilone \\ SS $89 \mathrm{~km} \mathrm{178+700} \mathrm{-} 71043$ Manfredonia FG (Italy) \\ phone: +39 0884 543493, fax: +39 0884543940 , e-mail: michele.guerra@portici.enea.it
}

\begin{abstract}
An exhaustive study has been carried out at the experimental centre ENEA of Monte Aquilone (Italy).

This paper arises from the need to feed the users who live in a remote place (e.g. in developing countries where the electrical system network isn't very large).

In particular, hybrid photovoltaic systems are considered since, as is well-known, they are very useful for feeding isolated loads thanks to the technological level reached and, above all, to the encouraging market forecast.
\end{abstract}

Two solutions have been examined and compared.

Key words: photovoltaic, stand-alone, optimization, hybrid systems.

\section{Introduction}

A PV-hybrid system feeding the actual people living in the village of Ginostra, Italy, has been examined.

Ginostra is a small village on Stromboli island, Italy. The village is made up of 140 houses but only 27 people live there the whole year round. The load requests of the island are certainly variable throughout the year considering that the flow of tourists in the months where solar radiation is higher leads to an increase in the population living on the island up to a maximum of 600 people in July and August [1].

This study looks into feeding electricity to the village through a mini-network stretching for a length of no less than $4 \mathrm{~km}$ by means of a hybrid power plant that complies with the specific needs of the residents. The results show different possibilities both in the configuration and in the optimization of the system management through different views. This paper analyzes the impact of different assumptions about the solar resource, fuel price, load expansion and required system reliability. Finally, great attention has been focused on the Minimum Renewable Fraction (MRF) which is the minimum allowable value of the annual portion of the system total annual electrical production originating from renewable power sources.

The goal of the local administration is to minimize the environmental impact that the energy supplied by the diesel generator could have on the delicate ecosystem of the island.

The study has been carried out at the experimental centre of Monte Aquilone (Italy) using the analyses of the data on the performance and efficiency of the conversion devices installed and two solutions have been examined and compared.

\section{The Hybrid System}

The solution suggested by the Authors consists of a stand-alone hybrid photovoltaic-diesel system. "Hybrid" system refers to a power generation system made up of one or more renewable sources (wind, solar, etc.) and a traditional diesel system acting as back-up in case of lack of the primary source [2]-[6].

The system analyzed by the Authors is made up of a photovoltaic generator, a diesel generator and a storage system that work together in an intelligent way.

The real hybrid plant is based on the following components [1]:

- Photovoltaic Generator with a rated power of $100 \mathrm{~kW}$;

- Diesel Generator with a power of $160 \mathrm{~kW}$;

- Battery storage with $\mathrm{C}_{10}=3000 \mathrm{Ah}, \mathrm{V}=400 \mathrm{~V}$;

- 3 integrated groups which are in parallel, each of them has a rated power of $50 \mathrm{~kW}$ and is made up of $\mathrm{AC} / \mathrm{DC}$ converter, inverter and static switch;

- a control and energy management system.

A specific integrated group of AC/DC converter, inverter and static switch has been purposely developed with particular technical solutions to supply the Hybrid Sys- 
tem with the necessary safety and reliability characteristics.

In normal conditions, the photovoltaic generator and the battery storage deliver power on a DC bus. The diesel generator is connected to the DC bus via controlled rectifiers but it can directly feed the network through a bypass switch (parallel connection). The PLC optimizes the PV generator contribution and assures the best continuity of service through the management of both battery storage and diesel generator [1].

\section{Choice of the Software}

Among the various available software [7], [8] the Authors have chosen the HOMER software (Hybrid Optimization Model for Electric Renewable) [9]. This software which simulates the different operating conditions, was developed by the National Renewable Energy Laboratory (U.S.) and has been used for choosing, in an optimal way, the various components of the plant.

HOMER is a micro-power optimization model that simplifies the task of evaluating power system designs in a variety of applications. As HOMER does both optimization and sensitivity analysis it makes easier to evaluate many possible system configurations of the large number of technology options and the variation in technology costs and availability of energy resources.

Using the data resulting from the experiments done at the centre of Monte Aquilone and those concerning the daily average loads of the village of Ginostra in the different

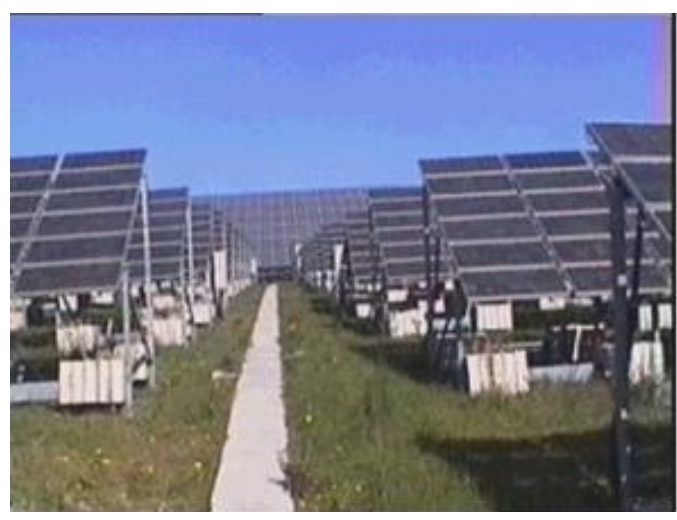

a) PV Generator months of the year HOMER has been able to simulate different system configurations according to the values of the daily ground average radiation throughout the year. Consequently, HOMER produces results in the shape of feasible configurations according to the increase in the Net Present Cost (i.e., the present value of the cost of installing and operating the system over the lifetime of the project, also referred to as lifecycle cost). The best configurations have been compared and examined on their economic and technical merits, by a sensitivity analysis which has compared the following quantities:

- $\quad$ estimation of the load curve;

- plant dimensioning;

- choice of the components configuration;

- productiveness evaluation;

- technical, economic appraisal;

- minimum allowable value of the annual renewable fraction (MRF).

\section{The Load Curve}

The load curve has been determined by suitably combining the real data of the experimental centre ENEA of Monte Aquilone, Italy (see Fig. 1 a and b), these data having been taken every two minutes during the reference year, and the daily average data concerning real users who live in summer in the village of Ginostra in Sicily, Italy.

By comparing the two load curves, the Authors have inferred a load curve of the seasonal users taken into account.

To determine the climatic parameters, an ENEA calculation program has been used in compliance with Standard

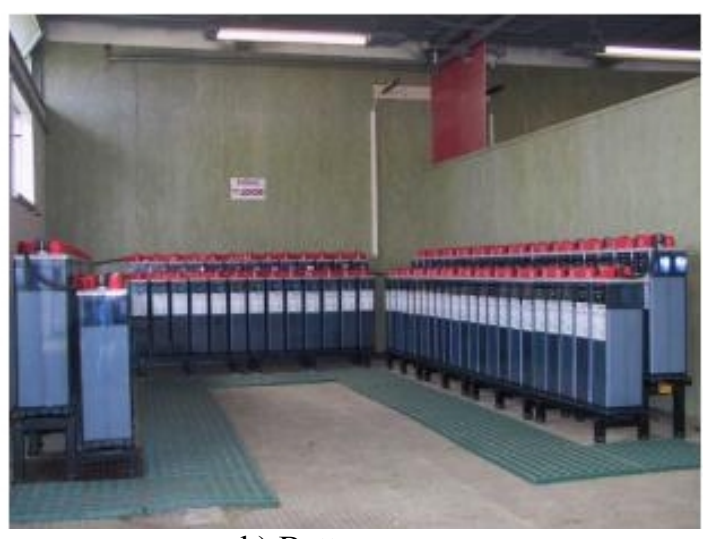

b) Battery room

Fig. 1 Hybrid photovoltaic plant made at the centre ENEA of Monte Aquilone (Italy)

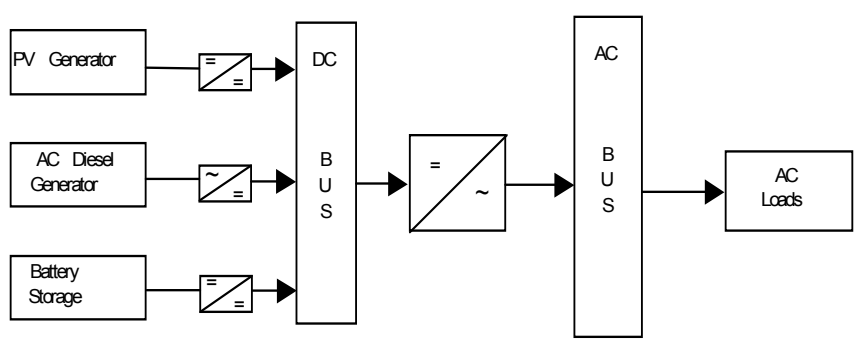

Fig. 2 Series Type

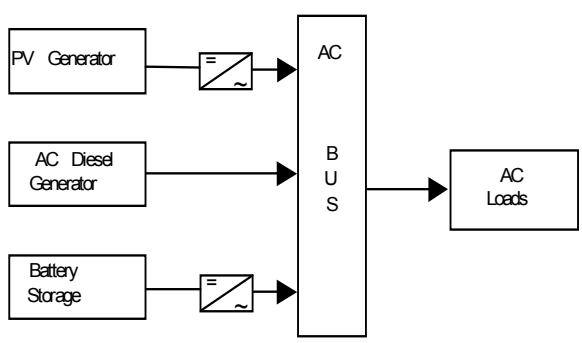

Fig. 3 Parallel Type 
UNI 8477. By entering all data relating to the place in question (i.e. tilt, azimuth, latitude) and the efficiency of the components employed, the Authors have obtained the daily average global radiation on the surface in question.

By the above data it is possible to design the photovoltaic plant, determine the battery capacity and the inverter power; the following two types have been examined and compared:

- the series type, with the generators connected to the dc power bus (see Fig. 2), this type being analogous to what carried out at the experimental centre ENEA of Monte Aquilone, Italy;

- the parallel type, with all components of the system directly connected between them by an ac power bus (see Fig. 3).

The comparison between the two types has led to the plant optimization.

\section{Tests and Results for the series system}

\section{A. Analysis of the Minimum Renewable Fraction}

The results of the simulations have shown that a minimum renewable fraction higher than $95 \%$ is obtained when the optimum capacity of the photovoltaic plant varies between $85 \mathrm{~kW}$ and $100 \mathrm{~kW}$, this value being in agreement with the capacity of the real system. As far as the size of the Diesel generator is concerned, the simulations carried out have resulted in the optimum power value of $25 \mathrm{~kW}$, equal to the peak value of the load curve. The size of the group of batteries is more or less half the size of the real system, that is to say $3000 \mathrm{Ah}$.

On the contrary, if we want to get a minimum renewable fraction of at least $70 \%$ through a $25 \mathrm{~kW}$ Diesel generator, we needn't have high-size conversion devices. This is due to a greater use of the Diesel according to both the quantity of energy produced and the number of working hours involved (see Fig. 4).

The main consequence is that if we decrease the fuel consumptions, even though the costs of the energy pro-

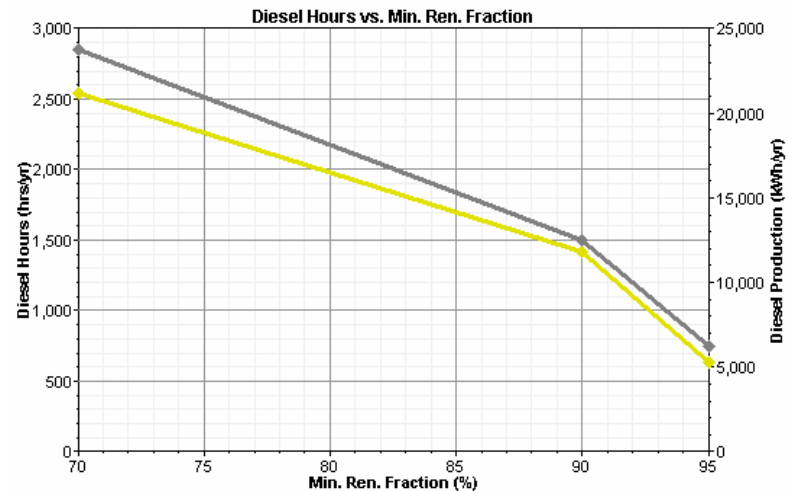

Fig. 4. Diesel Hours and Diesel Production vs. MRF. Diesel Hours are marked in yellow; Diesel Production are marked in grey $\left(\right.$ fixed Global Solar $=4.71 \mathrm{kWh} / \mathrm{m}^{2} / \mathrm{d}$ and Diesel Price $=$ $€ 0.33 / \mathrm{L})$ duced increase because of the highest Capital Costs, the level of pollution falls about 4 times.

The results actually show a close connection between the per cent values of renewable-source energy and the dimension of the system features. For example, once the MRF of the system total annual electrical production has been fixed, according to the values of solar radiation in the year, the optimum size of the photovoltaic generator varies in a remarkable way; the higher the MRF we want to get is the truer this turns out to be (see Fig. 5).

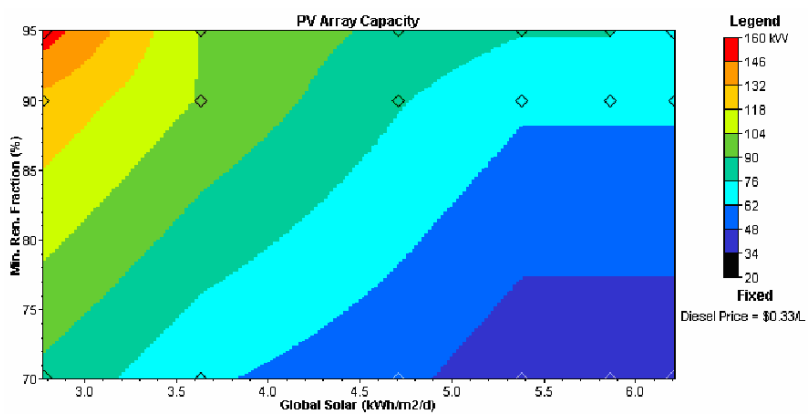

Fig. 5. PV Array Capacity vs. Global Solar and MRF.

You can notice that the level curves in Fig. 5, which represent the different optimum size of the PV generator, have a gradient that increases according to the increase in the MRF and the decrease in the daily radiation. On the contrary, the optimum size of the PV generator tends to be constant if the solar radiation is high: that is, if the real system was designed to work only in the summer months, the extent of the optimum PV generator for the system taken into consideration would depend only on the decision to have, load curves being equal, a more or less high MRF.

\section{B. Economic Analysis}

As far as the economic analysis of the system is concerned, as the MRF increases the Capital Cost (i.e., the total installation cost at the beginning of the project) of the system increases, this costs being about $2 / 3$ of the Global Cost of the system if a lifetime equal to 20 years is taken into consideration (see Fig. 6).

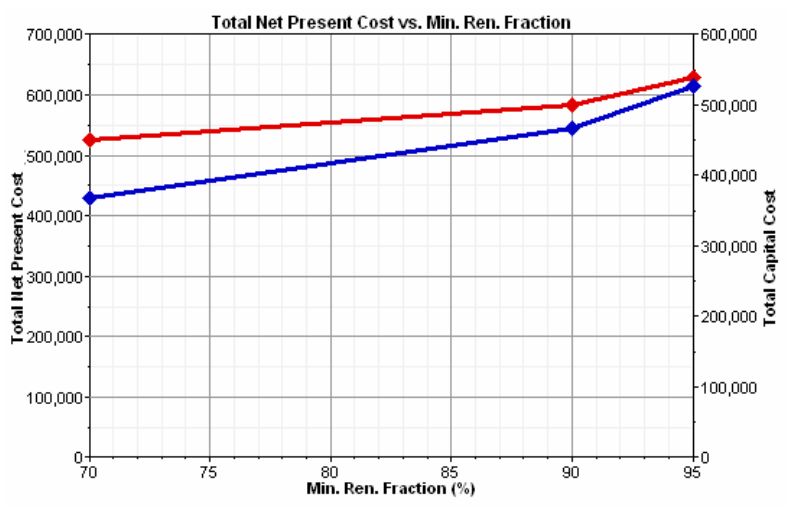

Fig. 6 Total Net Present Cost and Total Capital Cost vs. MRF (fixed Global Solar $=4.71 \mathrm{kWh} / \mathrm{m}^{2} / \mathrm{d}$ and Diesel Price = $€ 0.33 / \mathrm{L})$ 
An initial higher investment in PV technology can be amortized owing to the drop in costs due to a restricted use of the Diesel and so to a reduction of the fuel used. In actual fact you must necessarily pay the cost of the renewable technology if you want to get a high renewablesource production through a hybrid system. Small communities can bear this cost if it is encouraged by an appropriate financing policy.

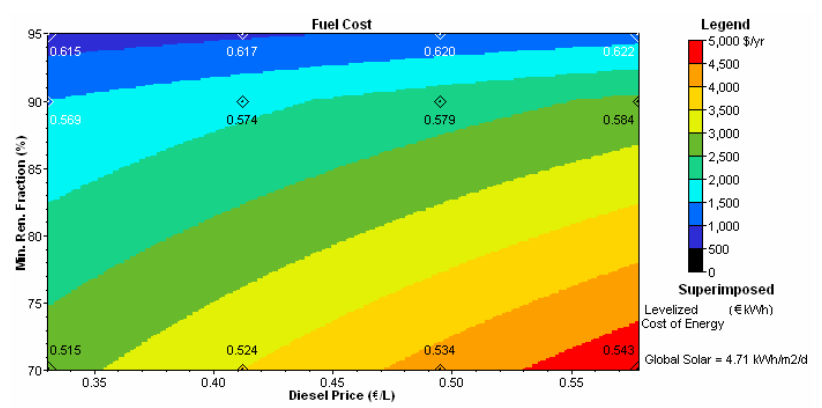

Fig. 7 Fuel Cost vs. Diesel Price and MRF.

For example, from the results got in Fig. 7, you can notice that if the increase in the MRF goes from $70 \%$ to $95 \%$ the cost of the $\mathrm{kWh}$ calculated considering the plant charges increases by $1 / 5$. On the contrary, the year's cost of the fuel used increases by about 5 times.

However a mechanism of economic incentives is still necessary because the fall in the costs is relative: the Total Net Cost (that is to say the installation and operating cost of the plant during its life cycle) of the system with an MRF equal to $95 \%$ is $25 \%$ higher than the system with an MRF equal to $70 \%$.

In spite of the trend of the Fixed Costs to approach the Total Net Cost according to the increase in the percentage of renewable-source energy, the costs of renewable technologies and conversion devices supporting the hybrid generation are still expensive.

The economic loss resulting from a hybrid system using a high MRF is well offset by a minimized environmental impact.

\section{Wear and tear on the devices}

Concerning the wear and tear on the devices you can notice the following.

- The batteries in the optimized system to get $95 \%$ of MRF and the optimized system to get $70 \%$ of MRF have a number of comparable cycles (see Fig. 8). The dimensions of the battery increase proportionally to the MRF as well as the quantity of energy they generate throughout the year.

- The Diesel is stressed for each percentage of MRF both as energy production and as number of starts a year.

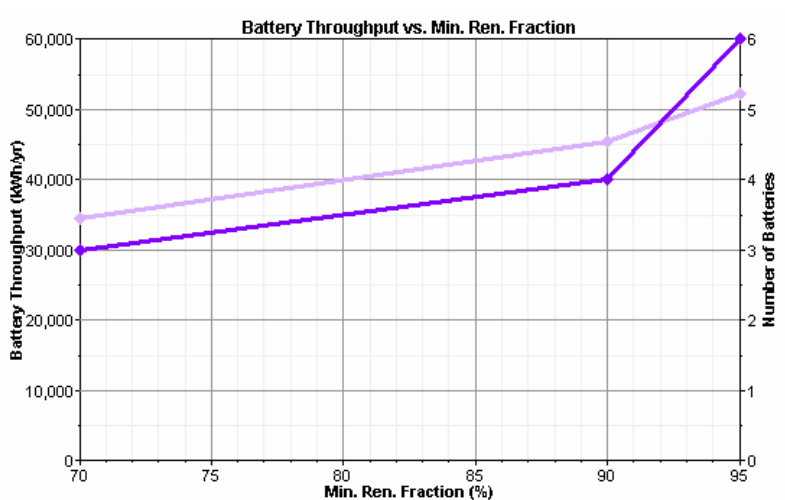

Fig. 8. Battery Throughput and Number of Battery vs. MRF. Battery Throughput is marked in grey; MRF is marked in blue (fixed Global Solar $=4.71 \mathrm{kWh} / \mathrm{m}^{2} / \mathrm{d}$, Diesel Price $=€ 0.33 / \mathrm{L}$ and Battery capacity per unit $=230 \mathrm{kWh}$ ).

We can conclude that, if we use a system with a high MRF, the wear and tear on the Diesel is minimized to such an extent that its life cycle can be remarkably prolonged. Moreover, the Diesel can work for high loads in accordance with the specifics of the makers (see Fig. 911).

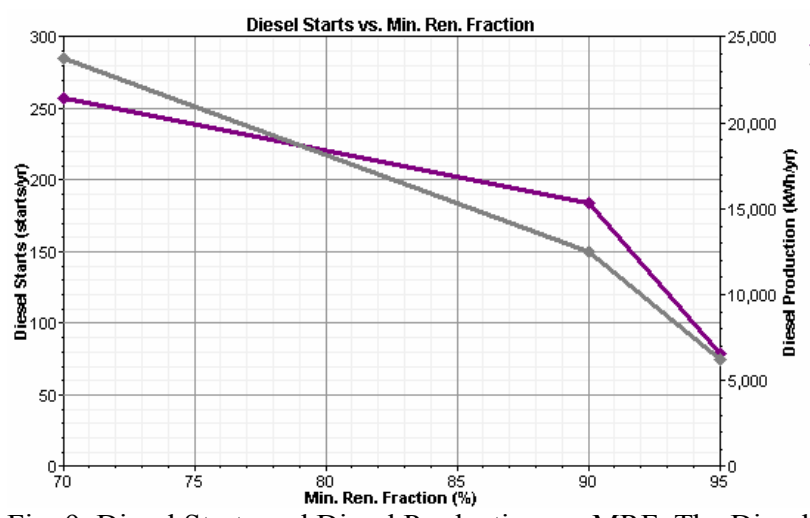

Fig. 9. Diesel Starts and Diesel Production vs. MRF. The Diesel Starts are marked in violet; the Diesel Production are marked in grey (fixed Global Solar $=4.71 \mathrm{kWh} / \mathrm{m}^{2} / \mathrm{d}$, Diesel Price = $€$ 0.33/L, PV Capital Multiplier =1, Dsl Lifetime $=10,000 \mathrm{hrs}$, Inverter Efficiency $=90 \%$ ).

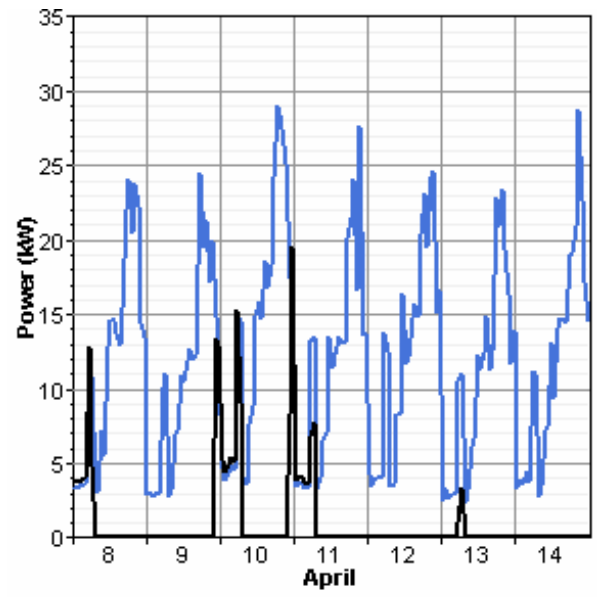

Fig. 10. Capacity curves for the hybrid system optimized for 95\% of the MRF (AC Primary Load is marked in blue; Diesel Power is marked in black). 


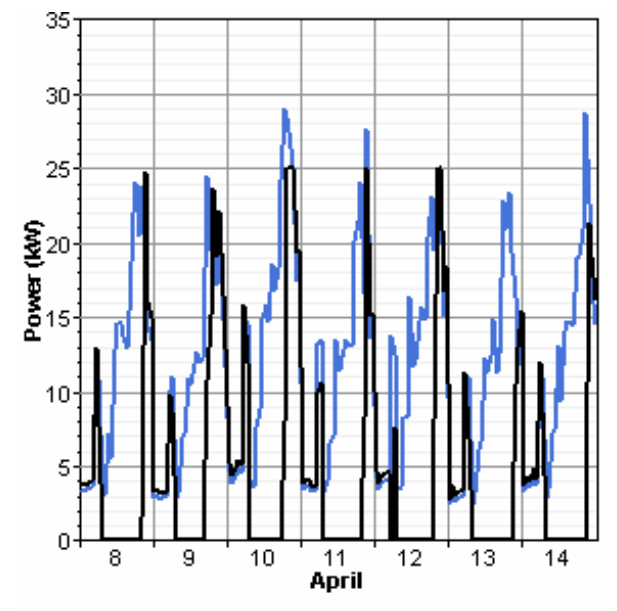

Fig. 11. Capacity curves for the hybrid system optimized for $70 \%$ of the MRF (AC Primary Load is marked in blue; Diesel Power is marked in black).

Although a generation with a high MRF is economically expensive, it allows many environmental advantages and the system management. In this way the system would need less maintenance charges and less fuel supply. Such system would be the ideal one for communities like the village of Ginostra because its flexibility would be particularly suited to the different types of load according to the seasons thus assuring a less maintenance charge of the devices constituting the system.

\section{Capacity of the Hybrid System according to the load increase}

The study on the optimum capacity of the hybrid system according to the load has been carried out by considering a system with $95 \%$ of MRF. To this end a $50 \%$ rise in the average load has been taken into account, i.e. many simulations have been done for dimensioning the hybrid system according to whether we want to feed different daily loads varying between $200 \mathrm{kWh}$ and $300 \mathrm{kWh}$ (see Fig. 12).

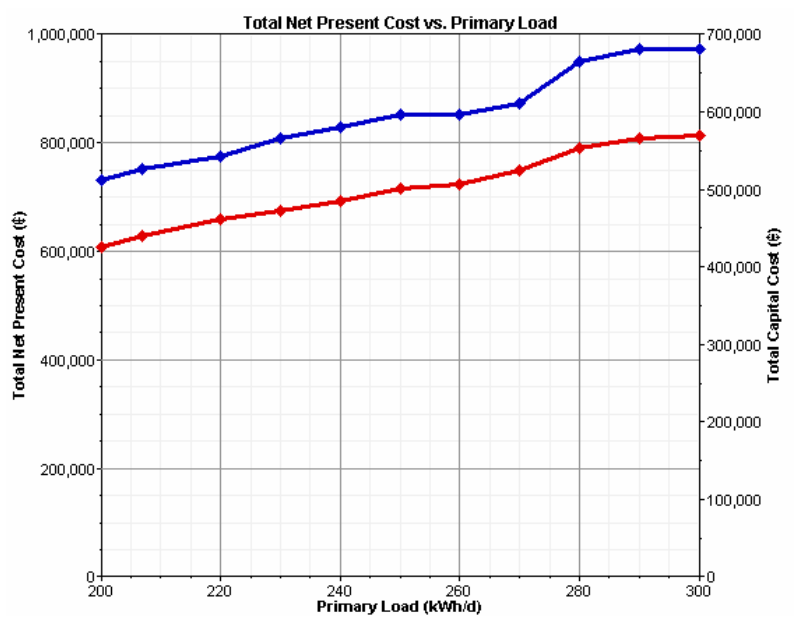

Fig. 12. Total Net Present Cost and Total Capital Cost vs. Primary Load. The Total Net Present Costs are marked in red; the Total Capital Costs are marked in blue.
The cost per kWh produced tends to be constant according to the rise in the total capacity of the system because, as the load increases, the software HOMER chooses to install a higher capacity of the PV generator and so it doesn't change the size of the Diesel generator in order to get the highest economic saving on the lifetime of the whole hybrid system. It is necessary to say that the configurations with greater Diesel generators have a bit higher cost, equal to $6 \% \div 10 \%$. So it would be better to choose systems with a higher-capacity Diesel to let the system be much more reliable in the event of failures of the PV generator.

\section{Tests and Results for the parallel system}

The simulations carried out with a parallel Diesel configuration haven't shown any fundamental differences compared with the similar series Diesel system, except for the conversion losses which are smaller.

Actually,

- $\quad$ as for the systems set on an MRF equal to $70 \%$ the conversion losses due to the series configuration lead to a rise in the system Total Net Cost equal to $2.5 \%$ compared with the similar parallel system (Capital Costs being equal),

- $\quad$ while, as for the systems set on an MRF of $95 \%$ both the series and parallel systems have equal costs if the configuration is the same.

The management strategies chosen for the two systems were in both cases the Load Following, even if in the series configuration the percentage relating to the choice of the Cycle Charging Strategy [4] [10] was higher.

The results have led to an optimum dimensioning of the PV generator comparable to the real capacity of the hybrid system of Ginostra.

\section{Conclusions}

From a technical point of view the solutions proposed by the Authors have turned out to be good and economically rather equivalent between them. From an economic point of view the hybrid plants made are not yet competitive compared to the traditional solution consisting in feeding the load only by the diesel generator.

However, it is necessary to consider that the choice of hybrid systems involves the reduction in harmful emissions and noises. Moreover, fuel, maintenance and wear of diesel generators are reduced, as these factors considerably affect remote places and developing countries.

The study carried out up to now on the optimization of the size and management strategies of a hybrid system so as to spread the renewable-source technologies in a reliable, safe way among isolated users has shown we don't need an excessive overdimensioning of the system components. 
On the contrary, it is important to have a dimensioning which allows the isolated users to be fed without supporting an excessive cost due to an investment in the expensive renewable technologies.

A good exploitation of the system components allows a high MRF with a more economical cost since there is a saving of the local environmental resources. In this way the system is highly reliable compared to the similar nonhybrid systems, whether traditional or renewable.

To finish we can be optimistic about the hybrid plant not only because a progressive reduction in the technology costs is taking place but also thanks to the possible public incentives that up to now have concerned, in Italy, only the grid-connected loads.

\section{References}

[1] G.Viglianesi, F. Minissale, G. Ubezio, "The Hybrid System Project with Mini-Grid In Ginostra, Village Of Stromboli Island", in Proc. $2^{\text {nd }}$ PV Hybrid and MiniGrid Conference 2004.

[2] D. Turcotte, M. Ross, F. Sheriff, "Photovoltaic hybrid system sizing and simulation tools: status and needs, in PV Horizon", Workshop on Photovoltaic Hybrid Systems, Montreal, September 10, 2001.

[3] T. D. Hund, S. Gates, "PV hybrid system and battery test results from Grasmere Idaho", in the 29th IEEE Photovoltaic Specialists Conference, New Orleans, May 2002.

[4] W. Kleinkauf, M. Ibrahim, O. Haas and B. Gruß, "Basics of Hybrid Technology for Grid Compatible Stand-Alone Plants".
[5] M. Asaoka S. Sakata, "A Hybrid Photovoltaic-Diesel Power Generation System for Miyako Island", Mitsubishi Electric advance, technical report, pp. 9-11, September 1997.

[6] A. N. Celik, "The system performance of autonomous photovoltaic-wind hybrid energy systems using synthetically generated weather data", Elsevier Renewable Energy, No. 27, pp. 107-121, 2002.

[7] G. Seeling-Hochmuth, "A Combined Optimization Concept for the Design and Operation Strategy of Hybrid PV Energy Systems", Solar Energy, Vol. 61, No. 2, pp. 77-87, Elsevier Science Ltd, 1997.

[8] G. C. Seeling, "Optimization Of PV-Hybrid Energy System Design And System Operation Control Using Genetic Algorithms", in Proc. of the 13th EC PV Conference, Nice, France, pp. 4, 1995.

[9] P. Lilienthal, L. Flowers, "HOMER: The Hybrid Optimization Model for Electric Renewable", in Proc. Windpower '95, American Wind Energy Association., Washington, DC, 27-30 March 1995, pp. 475-480.

[10] M. Sylos Labini, G. Delvecchio, M. Guerra, C. Lofrumento, F. Neri, "A Study for Optimizing the Management Strategies of a Hybrid Photovoltaic-Diesel Power Generation System", in Proc. of the International Conference on Renewable Energy and Power Quality - ICREPQ 2004, 31 March 1-2 April 2004, Barcelona, Spain.

[11] M. Sylos Labini, G. Delvecchio, F. Fraccalvieri, F. Neri, B. Valenzano, "A Theoretical Study for Supporting an Autonomous Diesel Power Plant with a Photovoltaic Generator", in Proc. of the International Conference on Renewable Energy and Power Quality - ICREPQ 2004, 31 March 1-2 April 2004, Barcelona, Spain. 